\title{
Retinoblastoma pT2 TNM Finding v8
}

National Cancer Institute

\section{Source}

National Cancer Institute. Retinoblastoma pT2 TNM Finding v8. NCI Thesaurus. Code C140717.

Intraocular tumor(s) with local invasion. (from AJCC 8th Ed.) 